\title{
ANÁLISIS DE ADNmt DE RESTOS ESQUELETALES DEL SITIO ARQUEOLÓGICO DE TIWANAKU Y SU RELACIÓN CON EL ORIGEN DE SUS CONSTRUCTORES
}

\author{
mIDNA ANALYSIS OF SKELETAL REMAINS FROM THE ARCHAEOLOGICAL \\ SITE OF TIWANAKU AND ITS RELATION TO THE ORIGIN OF ITS BUILDERS
}

\author{
Francisco Rothhammer*, Mauricio Moraga**, Mario Rivera***, Calogero M. Santoro****, \\ Vivien G. Standen****, Federico García** y Pilar Carvallo*****
}

\begin{abstract}
Las hipótesis sobre el origen de las poblaciones que construyeron Tiwanaku basadas en información lingüística y etnohistórica son contrastadas haciendo uso de ADN mitocondrial antiguo, aislado de restos esqueletales. Se analizaron 18 muestras de las cuales 13 rindieron amplificados para los marcadores amerindios. La distribución de haplogrupos (A: $8 \%, \mathrm{~B}: 15 \%, \mathrm{C}: 23 \%$, D: $23 \%$ y otros $31 \%$ ) relaciona genéticamente a la población estudiada con grupos amazónicos y quechuas actuales. El número de muestras analizadas no permite aún una subdivisión por fases cronológicas con el objeto de precisar más el origen de las poblaciones Tiwanaku. No obstante, la distribución de haplogrupos es significativamente diferente de aquella que caracteriza a los grupos aymara.
\end{abstract}

Palabras claves: Origen amazónico de las poblaciones Tiwanaku, restos esqueletales, ADNmt antiguo.

The origin of Tiwanaku populations hypothesized on the basis of linguistic and ethnohistorical information is tested using ancient mtDNA extracted from skeletal remains. 18 samples were analyzed of which 13 could be typed for amerindian haplogroups whose distribution (A: 8\%, B: 15\%, C: 23\%, D: 23\% y otros 31\%) relates genetically the remains from Tiwanaku to extant amazonian and quechua populations. The number of analyzed samples is still to small to allow a subdivision by chronological phases in order to establish more precisely the origin of the Tiwanaku population. Nevertheless, the haplogroup distribution is significantly different from the distribution that characterizes the aymara.

Key words: Amazonian origin of Tiwanaku populations, skeletal remains, ancient mtDNA.

La primera descripción del sitio arqueológico de Tiwanaku, para algunos investigadores uno de los más notables de Sudamérica, fue realizada alrededor de 1549 por Pedro de Cieza de León. Este cronista que destaca la monumentalidad de las construcciones de piedra no se limita a este aspecto, sino que indaga sobre sus orígenes mencionando que el lugar era el centro de Titiviraqodia, creador del mundo (Albarracin-Jordan 1996). Resulta interesante destacar que Cieza de León también se refiere a la conquista de Chucuito por los lupaqas (aymaras) bajo el mando de Cari (Gisbert et al. 1987).

Larga es la lista de estudiosos que a lo largo de 450 años escribieron sobre Tiwanaku, resultando difícil destacar los aportes de algunos, sin co- rrer el riesgo de ser injusto con los restantes. No obstante, es necesario indicar que fueron Stübel y Uhle (1892) quienes realizaron un análisis sistemático del sitio, relacionando de paso su origen con el de los aymaras. Si bien las especulaciones sobre las ruinas arquitectónicas de Tiwanaku alcanzaron en la primera mitad del siglo XX alturas insospechadas (Posnansky 1945), sólo las primeras excavaciones sistemáticas de Bennett (1933) permitieron establecer una secuencia cerámica estratigráfica. Posteriormente las excavaciones del Centro de Investigaciones Arqueológicas de Tiwanaku lideradas por Ponce Sanginés permitieron registrar una secuencia cultural completa. Más recientemente Browman (1981), Kolata (1986), Bermann (1987), Graffan (1989) y Albarracin-Jordan

\footnotetext{
* Programa de Genética Humana - ICBM, Facultad de Medicina, Universidad de Chile; Centro de Investigaciones del Hombre en el Desierto, Universidad de Tarapacá, Arica, Chile. frothham@machi.med.uchile.cl

** Programa de Genética Humana - ICBM, Facultad de Medicina, Universidad de Chile.

*** Universidad Bolivariana, Iquique. mrivera@execpc.com

**** Centro de Investigaciones del Hombre en el Desierto, Departamento de Arqueología y Museología, Facultad de Ciencias Sociales, Administrativas y Económicas, Universidad de Tarapacá, Arica, Chile. csantoro@uta.cl; vstanden@uta.cl

***** Departamento de Biología Celular y Molecular, Facultad de Ciencias Biológicas, Pontificia Universidad Católica de Chile.
} 
(1996), entre otros, han generado nuevos aportes interpretativos de gran relevancia. En efecto, los estudios realizados por Kolata (1986) en Pampa Koani permitieron postular que el sustento económico de Tiwanaku provenía del aprovechamiento agrícola de una extensa zona de camellones ubicada a unos $12 \mathrm{~km}$ de distancia del emplazamiento principal. Actualmente se ha postulado que una brusca y prolongada disminución de las precipitaciones ocurrida alrededor del año 1000 a.p. produjo el declinamiento y la posterior desarticulación del imperio.

El lingüista peruano Alfredo Torero (1970, 1987) sostiene que eran cuatro lenguas las que se hablaban en el altiplano en el siglo XVI; estas eran el aymara, el quechua, el puqina y el uruquilla. Las áreas geográficas de distribución de las poblaciones que poseían estos dialectos difieren de las actuales, de modo que el uruquilla habría sido hablado principalmente en el área circundante al Lago Titicaca, mientras que el puqina estaba circunscrito a los Andes surcentrales incluyendo la región de Tiwanaku, el aymara a la región del Río Pampas en el departamento de Ayacucho y el quechua a la costa y sierra centrales del Perú. Torero (1970, 2003) con base en un análisis glotocronológico propone un fechado para la expansión inicial del quechua (1.100 a.p.) y del aymara (800 a.p.). Este autor también considera, en contraposición a las ideas de Stübel, Uhle y Ponce Sanginés entre otros, que una invasión aymara proveniente del norte estaría vinculada con el ocaso de Tiwanaku, cuyos constructores habrían sido los puqinas collavinos. Otros investigadores, recurriendo fundamentalmente a información etnohistórica (Bouysse-Cossagne 1987; Espinoza Soriano 1980; Gisbert et al. 1987) difieren respecto del origen geográfico de la supuesta invasión aymara.

Dados los avances recientes de la antropología molecular y la experiencia que hemos ganado en este campo, intentaremos contrastar en este trabajo las dos hipótesis básicas existentes sobre el origen de los constructores del imperio Tiwanaku, realizando un análisis de restos esqueletales exhumados en yacimientos arqueológicos pertenecientes a esta cultura.

\section{Materiales y Métodos}

Las 18 muestras utilizadas fueron exhumadas en Tiwanaku en los lugares de Akapana (3), Akapa- na Este (4) Chiji Jawira (2), Mollo Kontu (3) y Putuni (6), durante trabajos de terreno realizados por Alan Kolata y colaboradores durante los últimos cinco años.

ADNmt fue extraído a partir de fragmentos de costillas, clavículas, falanges o diáfisis de huesos largos. Se utilizó un fragmento no superior a $1 \mathrm{~cm}^{2}$. Los fragmentos de hueso utilizados fueron pulidos de manera de eliminar la cortical externa presumiblemente contaminada con ADN reciente debido a manipulaciones previas. Posteriormente las muestras fueron fragmentadas con una herramienta de corte e irradiadas con luz UV por 15 minutos por cada lado. Durante todos los procedimientos se utilizó mascarilla, delantal y guantes de látex estériles desechables. Todos los materiales desechables fueron cambiados muestra a muestra y tanto las superficies como las herramientas utilizadas fueron limpiadas con hipoclorito al $10 \%$ y enjuagadas con agua bidestilada estéril. Los fragmentos de hueso fueron pulverizados por medio de un molino enfriado por nitrógeno líquido (Spex CertiPrep). Los viales de molienda de policarbonato usados en este fueron lavados entre muestra y muestra, enjuagados con agua, tratados por 5 minutos con ADNzap (Ambion) para destruir cualquier traza de ADN y enjuagados repetidas veces con agua bidestilada estéril. La extracción de ADN a partir de las muestras de hueso se realizó utilizando una modificación de la metodología descrita por Höss y Pääbo (1993). Aproximadamente 0,5 a 1 gr de la muestra, previamente pulverizada, se incubaron por 24 horas en $8 \mathrm{ml}$ de EDTA 0,5 M pH: 8,0, a temperatura ambiente con agitación esporádica. La muestra parcialmente descalcificada se colectó por centrifugación descartándose el sobrenadante. Se agregaron $5 \mathrm{ml}$ de tampón de digestión (tiocianato de guanidinio $5 \mathrm{M}$, Tris- $\mathrm{HCl} \mathrm{pH}: 7,2,100 \mathrm{mM}$ ) y se incubó a $55^{\circ} \mathrm{C}$ por 8 a 16 horas con agitación. Las muestras se centrifugaron descartándose el precipitado. Los sobrenadantes se trasladaron a tubos nuevos y se agregaron $50 \mathrm{ml}$ de suspensión de sílica, incubándose por 10 minutos a temperatura ambiente para unir el ADN a la sílica. La sílica se lavó repetidas veces con tampón de extracción, etanol $70 \%$ y acetona, para finalmente diluir el ADN con tampón TE (10 mM Tris-HCl pH: 8,5; 0,1 mM EDTA). Todos los procedimientos considerados en la extracción se realizaron en un laboratorio dedicado exclusivamente al procesamiento 
de muestras antiguas. Los equipos utilizados fueron limpiados regularmente con ADNzap (Ambion) de modo de eliminar cualquier riesgo de contaminación entre muestras. Se utilizó material plástico estéril desechable y tanto los reactivos como las muestras se manipularon siempre bajo campana de flujo laminar. En todas las extracciones se incluyó uno o dos controles blanco conteniendo sólo los reactivos.

Debido a que las muestras antiguas por lo general rinden ADN altamente degradado con tamaños medios no superiores a los 150 ó 200 pb (Pääbo et al.1988; Pääbo 1989) se usó un grupo de partidores diseñados de modo de amplificar fragmentos en el rango de 75 a $121 \mathrm{pb}$ (Handt et al. 1996).

La amplificación por PCR del ADN extraído desde las muestras antiguas se realizó utilizando 2,5 unidades de Ampli-taq Gold ADN polimerasa (Applied Biosystems), el tampón suministrado con la enzima dNTPs $200 \mathrm{mM}$ c/u, 25 pmoles de cada partidor y $100 \mathrm{mg}$ de BSA, con el fin de contrarrestar el efecto inhibidor sobre la taq-polimerasa de algunos contaminantes que copurifican con el ADN. El programa de PCR utilizado considera: denaturación inicial, $95^{\circ} \mathrm{C}$ por 9 minutos, 45 ciclos de denaturación, $93^{\circ} \mathrm{C}$ por 45 segundos; apareamiento, $55^{\circ} \mathrm{C}$ por 45 segundos; elongación, $72^{\circ}$ por 45 segundos, y elongación final a $72^{\circ} \mathrm{C}$ por $3 \mathrm{mi}-$ nutos. Los productos de PCR se resolvieron por electroforesis en gel de NuSieve-Agarosa al 3\%.

Los haplogrupos A, C y D fueron analizados mediante el uso de enzimas de restricción. Se utilizó Hae III para el haplogrupo A, Hinc II para el haplogrupo C y Alu I para el haplogrupo D. Los fragmentos de restricción resultantes así como el producto de PCR que incluye la región intergénica COII/tRNA ${ }^{\text {Lys }}$ del ADNmt, que define el haplogrupo $\mathrm{B}$, fueron analizados por electroforesis en gel de Nusieve-Agarosa (3:1) al 3\% (FMC BioProducts). Los fragmentos de ADN se visualizaron en el gel por tinción con bromuro de etidio.

El análisis de la información genética comprendió el cálculo de distancias genéticas (Nei 1978). La significación estadística de éstas fue obtenida calculando probabilidades exactas utilizando el método de Raymond y Rousset (1995). Se generó además un dendrograma utilizando el método neighbor-joining (Saitou y Nei 1987).

\section{Resultados}

Del total de 18 muestras analizadas, 13 rindieron amplificados para algunos de los cuatro fragmentos de PCR polimórficos en amerindios, permitiéndonos estimar las frecuencias que presenta cada haplogrupo a través de métodos de máxima verosimilitud.

De las muestras haplotipificadas $69 \%$ corresponde a uno de los cuatro haplogrupos descritos en aborígenes americanos, mientras que las restantes $(31 \%)$ resultaron negativas para los marcadores estudiados. Estos últimos linajes, debido a la antigüedad de las muestras, no pueden ser atribuidos a mestizaje, representando posiblemente nuevos linajes mitocondriales no descritos en poblaciones recientes, presumiblemente perdidos como resultado de los profundos cambios demográficos que sufrieron las poblaciones originarias de América tras la llegada de los invasores europeos. Otra alternativa sería que se encuentren en tan baja frecuencia en las poblaciones aborígenes actuales que no se han detectado en los muestreos realizados o bien han sido confundidos con linajes no amerindios introducidos por flujo génico.

Las frecuencias estimadas para los cuatro haplogrupos amerindios principales oscilan entre el $8 \%$ para el haplogrupo A y el 23\% para los haplogrupos $\mathrm{C}$ y $\mathrm{D}$, alcanzando el haplogrupo $\mathrm{B}$ una frecuencia de $15 \%$. Estas frecuencias difieren de las observadas en las poblaciones aymara y atacameña actuales, en las cuales el haplogrupo B representa cerca del 60\% (Rocco et al. 2002).

Las frecuencias de los haplogrupos mitocondriales de las muestras arqueológicas fueron comparadas con frecuencias para las poblaciones aymara, atacameña y quechua (Rocco et al. 2002; Rodríguez-Delfin et al. 2001) ya mencionadas, así como con datos de poblaciones prehistóricas del Valle de Azapa (Moraga et al. 2001) y de aborígenes de la Amazonia (Santos et al. 1996). La inspección de la Tabla 1 revela que las frecuencias de los cuatro haplogrupos diferencian a aymaras y atacameños del resto de las poblaciones, observándose además que los haplogrupos $\mathrm{A}, \mathrm{B}$ y $\mathrm{C}$ presen$\tan$ frecuencias similares en grupos tiwanakotas, quechuas y aborígenes de la Amazonia.

La matriz de distancias de Nei (Nei 1978) construida a partir de las frecuencias relativas de haplogrupos se muestra en la Tabla 2. Resulta interesante 
Tabla 1. Frecuencia de haplogrupos amerindios de ADNmt en restos esqueletales de Tiwanaku y el valle de Azapa y en poblaciones amazónicas, aymaras, atacameñas y quechuas contemporáneas. El tamaño de muestra para cada población se indica entre paréntesis.

Amerindian mtDNA haplogroup frequencies in skeletal remains from Tiwanaku and Azapa Valley and in extant indigenous populations. Sample size of each populations is given in parenthesis.

\begin{tabular}{lcccccl}
\hline $\begin{array}{c}\text { Poblaciones } \\
\text { (N) }\end{array}$ & $\begin{array}{c}\text { Haplogrupo } \\
\mathrm{A}\end{array}$ & $\begin{array}{c}\text { Haplogrupo } \\
\mathrm{B}\end{array}$ & $\begin{array}{c}\text { Haplogrupo } \\
\mathrm{C}\end{array}$ & $\begin{array}{c}\text { Haplogrupo } \\
\mathrm{D}\end{array}$ & Otros & Autor \\
\hline Tiwanaku (13) & 0,080 & 0,150 & 0,230 & 0,230 & 0,310 & Este estudio \\
Amazonas (139) & 0,295 & 0,281 & 0,273 & 0,137 & 0,014 & Santos et al. 1996 \\
Quechua (19) & 0,263 & 0,368 & 0,0530 & 0,316 & 0,000 & Rodríguez-Delfin et al. 2001 \\
Aymara (120) & 0,075 & 0,567 & 0,183 & 0,158 & 0,017 & Rocco et al. 2001 \\
Atacameño (24) & 0,083 & 0,625 & 0,250 & 0,042 & 0,000 & Rocco et al. 2001 \\
Valle de Azapa (32) & 0,313 & 0,219 & 0,313 & 0,031 & 0,125 & Moraga et al. 2001 \\
\hline
\end{tabular}

Tabla 2. Distancias de Nei (Nei 1978), calculadas a partir de las frecuencias de los haplogrupos de ADNmt para Tiwanaku, valle de Azapa y poblaciones indígenas actuales.

Nei's (1978) distances computed from mtDNA haplogroup frequencies for Tiwanaku, Azapa valley, and extant indigenous populations.

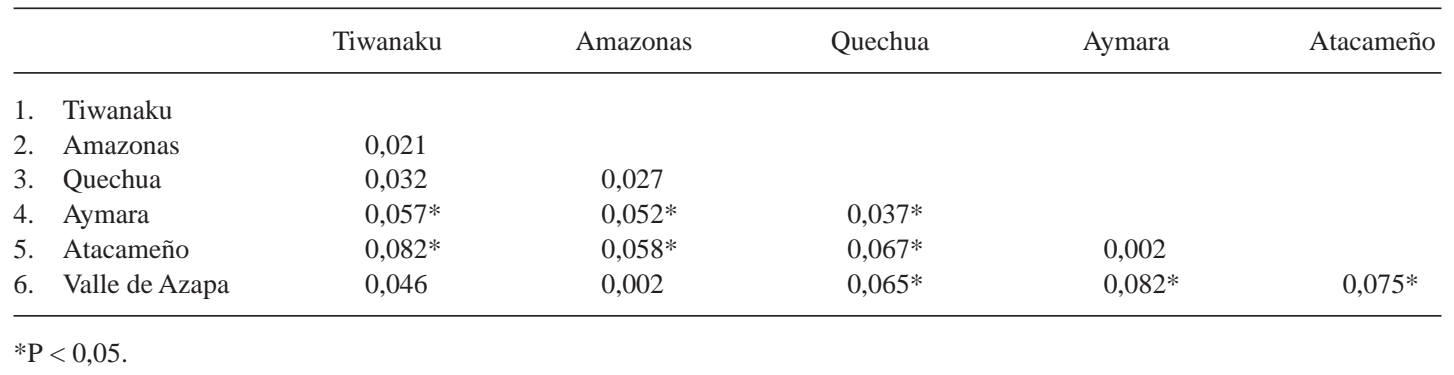

constatar que la distancia existente entre Tiwanaku, las poblaciones prehistóricas del Valle de Azapa, los grupos amazónicos y los quechuas es pequeña y no significativa, mientras que distancias mayores se aprecian entre éstas y las etnias originarias del norte de Chile avalando el análisis realizado por inspección. Cabe mencionar que en la muestra de poblaciones prehistóricas del Valle de Azapa predominan los grupos de los períodos arcaico tardío, formativo y medio, razón que explicaría su proximidad a las poblaciones amazónicas. Los grupos del período Intermedio Tardío y Tardío tienden a agruparse más bien con los aymaras (Moraga et al. 2003).

El dendrograma construido a partir de la matriz de distancias de Nei (1978) (Figura 1) pone de manifiesto esta situación y muestra a Tiwanaku agrupado junto a quechuas, aborígenes amazónicos y poblaciones del Valle de Azapa, sugiriendo fuertemente una vinculación ancestral.

\section{Discusión}

El hallazgo más interesante de este trabajo es, sin duda, la proximidad genética de los restos esqueletales de Tiwanaku a los quechuas y a los aborígenes de la Amazonia, deducida a partir de distancias no significativas.

Aún cuando el número de individuos analizados es relativamente pequeño y podría en consecuencia ser motivo de dudas sobre los resultados, nuestra experiencia indica que la distribución de haplogrupos mitocondriales es poco sensible a reducciones del tamaño muestral. Por otra parte, estudios realizados en el Valle de Azapa indican que a partir del período Medio aumenta significativamente la frecuencia del haplogrupo B, que es característico de los aymara, coincidiendo con una posible llegada de este grupo étnico al altiplano (Moraga et al. 2003). A su vez estudios genéticos realizados en restos óseos del cementerio tiwa- 


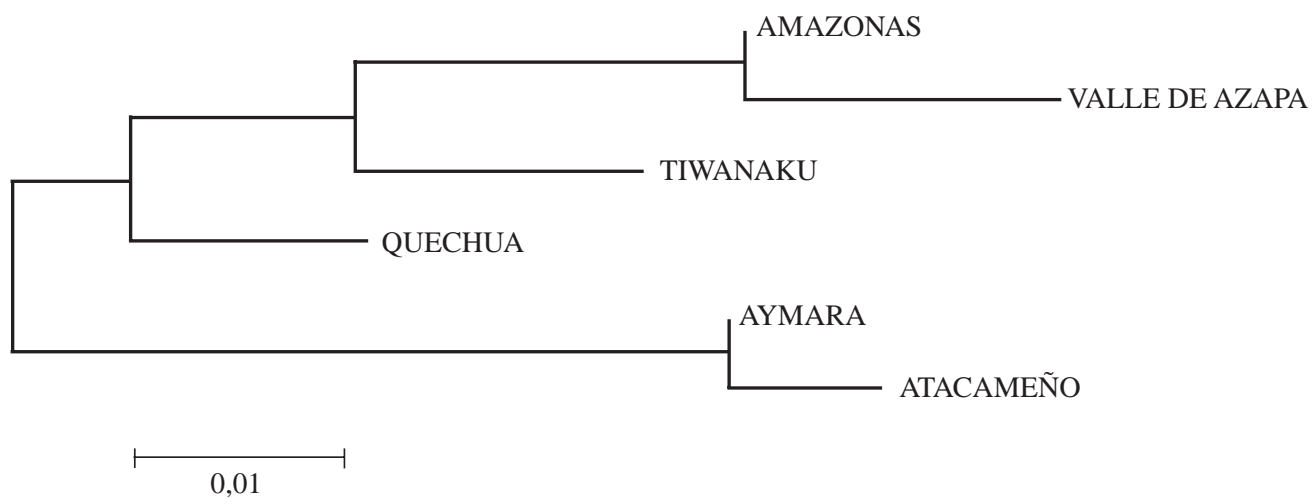

Figura 1. Dendrograma neighbor-joining construido a partir de distancias de Nei (1978).

Neighbor-joining dendrogram based on Nei's distances (1978) .

nacota de Tiraska por miembros del Proyecto Boliviano-Finlandés para la Amazonia Boliviana avalan nuestros resultados (Korpisaari, comunicación personal).

Por otra parte, es preciso agregar que parte de las diferencias también podrían ser explicadas considerando el tiempo transcurrido, los posibles movimientos poblacionales en el área de Tiwanaku y la marcada disminución del tamaño de las poblaciones andinas después de la llegada de los invasores europeos. En efecto, no podemos descartar que muestras mayores obtenidas en otros sitios de la región de Tiwanaku arrojen resultados algo diferentes.

No obstante, las distancias separan consistente y significativamente a tiwanacotas, quechuas y grupos amazónicos, de aymaras y atacameños indicando un origen diferente. En efecto, nuestros resultados avalan la hipótesis de un origen no aymara de los constructores de Tiwanaku. Información reciente obtenida por nuestro grupo de trabajo y basada en el análisis de ADNmt vincula a aymaras y atacameños más bien a grupos de habla pano del Chaco fortaleciendo la hipótesis lingüística de Torero (1987) que sostiene que los aymaras habrían llegado al altiplano cerca del 1.100 a.p.

Según Albarracin-Jordan (1996) no existe evidencia de cambios bruscos, sino que más bien se observa una continuidad arqueológica entre
Tiwanaku y Uma-Pacajes, avalando la tesis de Kolata (1993) respecto de la degradación climática, y restando soporte a la hipótesis de que una invasión aymara post-Tiwanaku habría estado relacionada con su desarticulación. A partir de esta degradación se habrían estructurado en el área circum-Titicaca grupos políticos con participación aymara, que podrían haber enfrentado primero a los inca y luego a los europeos.

La similitud encontrada entre quechuas y Tiwanaku no indica necesariamente que los primeros están vinculados a la construcción de lo que actualmente se encuentra en el sitio arqueológico. También es posible que quechuas y tiwanakotas hayan compartido ancestros comunes cuyo origen es la región selvática de Bolivia, como insinúan recientes estudios de ADNmt realizados por nosotros.

No cabe duda de que nuevas (y también antiguas) hipótesis basadas en el análisis de información arqueológica y bioantropológica podrán ahora ser contrastadas utilizando el ADNmt antiguo como herramienta. Los vínculos de las poblaciones prehistóricas andinas con la floresta tropical, sorprendentemente poco ponderadas, constituyen un buen modelo para llevar a cabo este propósito.

Agradecimientos: Los autores agradecen el financiamiento recibido a través del proyecto Fondecyt N ${ }^{\circ} 1010131$. 


\section{Referencias Citadas}

Albarracin-Jordan, J.

1996 Tiwanaku. Arqueología Regional y Dinámica Segmentaria. Plural Editores, La Paz.

Bennett, W.C.

1933 Archaeological hikes in the Andes. Natural History Vol. XXXIII, $\mathrm{N}^{\circ}$ 3:169-174.

Bermann, $M$.

1987 Tiwanaku houses from Lukurmata: An overview. En

The Technology and Organization of Agricultural Production in the Tiwanaku State, Segundo informe preliminar del Proyecto Wila Jawira, editado por A. L. Kolata, Ch. Stanish y O. Rivera. University of Chicago, Chicago.

Bouysse-Cossagne, $\mathrm{T}$.

1987 La Identidad Aymara. Aproximación Histórica (Siglo $X V$, Siglo XVI). Hisbol, La Paz.

Browman, D.

1981 New light on andean Tiwanaku. American Scientist 69:408-419.

Espinoza Soriano, W.

1980 Los fundamentos lingüísticos de la etnohistoria andina. Revista Española de Antropología Americana:143-149.

Gisbert, T., S. Arze y M. Cajías

1987 Arte Textil y Mundo Andino. Gisbert y Cía., La Paz.

Graffan, G.

1989 The agricultural aqueduct at Chiripa. En The Archaeology and Paleoecology of Lukurmata, Bolivia. Segundo informe preliminar del Proyecto Wila Jawira, editado por A. L. Kolata, Ch. Stanish y O. Rivera. University of Chicago, Chicago.

Handt, O., M. Krings, R. Ward y S. Pääbo

1996 The retrieval of ancient human DNA sequences. American Journal of Human Genetics 59:368-376.

Höss, M. y S. Pääbo

1993 DNA extraction from pleistocene bones by a silicabased purification method. Nucleic Acids Research 16: 3913-3914.

Kolata, A.

1986 The agricultural foundations of the Tiwanaku state: a view from the hearthland. American Antiquity 51:748-752. 1993 The Tiwanaku: Portrait of an Andean Civilization. Blackwell, Cambridge.

Moraga, M., E. Aspillaga, C. Santoro, V. Standen, P. Carvallo y

F. Rothhammer

2001 Análisis de ADN mitocondrial en momias del norte de Chile avala hipótesis de origen amazónico de poblaciones andinas. Revista Chilena de Historia Natural 74:719-726.

Moraga, M., C. Santoro, V. Standen, P. Carvallo y F. Rothhammer 2004 Microevolution in prehistoric Andean populations: Chronologic mtDNA variation in the desert valleys of northern Chile. American Journal of Physical Anthropology, en prensa.
Nei, M.

1978 Estimation of average heterozygosity and genetic distance from a small number of individuals. Genetics 89:583-590.

Pääbo, S.

1989 Ancient DNA: extraction, characterization, molecular cloning, and enzymatic amplification. Proceedings of the National Academy of Science USA 86:1939-1943.

Pääbo, S., J. Gifford y A.C. Wilson

1988 Mitochondrial DNA sequences from a 7000-year old brain. Nucleic Acid Research 16:9775-9787.

Posnansky, A.

1945 Tihuanacu: Cuna del Hombre Americano, Vols., 1 y 2. J.J. Austin, New York.

Raymond, M. y F. Rousset

1995 An exact test for populations differentiation. Evolution 49:1280-1283.

Rodríguez-Delfin L.A., V.E. Rubin-de-Celis y M.A. Zago

2001 Genetic diversity in an Andean populations from Peru and regional migration patterns of Amerindians in South America: data from Y chromosome and mitochondrial DNA. Hum Hered 51(1-2): 97-106.

Rocco, P., G. Morales, M. Moraga, J.F. Miquel, F. Nervi, E.

Llop, P. Carvallo y F. Rothhammer

2002 Composición genética de la población chilena. Distribución de polimorfismos de DNA mitocondrial en grupos aborígenes y en la población mixta de Santiago. Revista Médica de Chile 130:125-131.

Saitou, N. y M. Nei

1987 The neighbor-joining method: a new method for reconstructing phylogenetic trees. Molecular Biology Evolution 4:406-25.

Santos, S.E., A.K. Ribeiro-Dos-Santos, D. Meyer y M.A. Zago 1996 Multiple founder haplotypes of mitochondrial DNA in Amerindians revealed by RFLP and sequencing. Annals of Human Genetics 60:305-319.

Stüebel, M. y M. Uhle

1892 Die Ruinenstätte von Tiahuanaco im Hochlande des Alten Peru: Eine Kulturgeschichtliche Studie auf Grund Selbständiger Aufnahmen. Verlag Karl W. Hiersemann, Leipzig.

Torero, A.

1970 Lingüística e historia en la sociedad andina. Actas del XXXIX Congreso Internacional de Americanistas:230-264. 1987 Lenguas y pueblos altiplánicos en torno al siglo XVI. Revista Andina 5:329-405.

2003 Idiomas de los Andes, Lingüística e Historia. Instituto Francés de Estudios Andinos, Editorial Horizonte, Lima. 